\title{
Chapter 12 \\ Considerations on Governing Heritage as a Commons Resource
}

\author{
Peter G. Gould
}

\section{Introduction}

Recent years have seen widespread scholarly interest in applying the concept of the "commons" to an array of environmental, economic, social, and technical challenges. Literatures from law to environmental science to urban design are alive with discussions of "new commons" and "knowledge commons" and various other permutations of the concept. Archaeologists and heritage practitioners are no exception and, although the literature addressing the commons concept in this field is still limited, it is not too early to evaluate what the existing discourse means, and whether and how it might add value to practice in heritage management.

Certainly there is ample motivation for doing so. Among archaeologists, there is widespread revulsion over the exclusion, disempowerment, and impoverishment of indigenous communities with traditional claims to archaeological, cultural, and natural heritage sites (Meskell 2012; Dowee 2009). Objections arise to a process of commodification that repackages customary practices and sites to appeal to visiting tourists while disenfranchising local communities (Herrera 2014; Herrera Wassilowsky 2013). Critiques have been made of the destructive impact on heritage of globalized economic development (Labadi and Long 2010). Archaeologists are frustrated over the failure to address looting and the antiquities trade that spawns it (Brodie and Tubb 2002). Distress has been voiced over the fact that international systems often fail to protect even the most iconic sites from trampling by tourists or the consequences of uncontrolled growth in the vicinity of archaeological sites (Comer 2012). The beguiling appeal of the commons is that seems to represent a community-based solution to heritage management that is inclusive, responsive to local needs, and beneficial to those with the most intimate connections to

P.G. Gould ( $₫)$

University of Pennsylvania Museum of Archaeology and Anthropology,

Philadelphia, PA, USA

e-mail: pgould8@gmail.com 
archaeological sites and heritage. The idea is that the commons present solutions to controlling, protecting, and developing tangible and intangible heritage that simultaneously will be both ethical and practically effective.

Although the published literature in archaeology and heritage management to date is limited, this is a good time to step back and evaluate the implications and requirements if those hopes are to be fulfilled. In particular, there is a disconnect in the literature to date between optimism expressed about the applicability of the commons idea and practical exploration of the mechanisms through which the benefits of the commons can be realized. That mechanism is governance, the institutional rules and structures through which true commons are managed. The objective of this chapter is to bring that crucial issue, which is deeply embedded in scholarly work on the commons in other disciplines, into the center of the commons discourse in archaeology and heritage.

\section{The Commons in Cultural Heritage Management}

The meaning of the term "commons" will be explored later. First, the literature within archaeology merits brief review. Mention of the "global commons" in culture and heritage has been intermittent for some years. Cunningham (1991) some years ago considered whether Indigenous knowledge constituted a global commons, and Arizpe (2000) explored at the turn of the millennium whether cultural heritage amounted to a global cultural commons. Scholarship on the commons in cultural heritage, as in other fields, has grown markedly since 2009, when the academic and public profile of the commons concept rose markedly after the late Elinor Ostrom, the intellectual founder of rigorous commons analysis, was awarded the Nobel Prize in economics. In the most comprehensive volume to date focused on the topic, Bertacchini et al. (2012) sought to define the domain of the "cultural commons," incorporating both theoretical papers and applied analyses of the commons attributes identified in landscapes, fashion and design, national gastronomy, World Heritage Sites, cultural heritage, and emergent "commons" such as social networks, virtual gaming, and crowdsourcing platforms. Alonzo González (2014, 2015; see also Chap. 11 this volume) has critically assessed the impact on communities' relations to their heritage from privatized or public management of intangible heritage and explored examples of communally managed alternatives. Colloredo-Mansfield and Antrosio (2009) identified a failing commons in an Andean village attempting to build a business based on traditional artisanship. Pyburn (Chap. 13 this volume) explored the consequences of applying Ostrom's governance principles to an archaeological research and tourism development project in a community in Belize.

In a separate vein, Carman (2005) appealed to Ostrom's (1990) commons governance principles to propose a tentative basis for constituting the commons as an alternative basis to determine the value of archaeological and heritage resources. Comer (2014a, b) has argued that heritage is a public good, inherently a commons concept, and needs to be managed as such by government authorities on a global 
scale. A session of the Seventh World Archaeological Congress in 2013 at the Dead Sea, Jordan produced seven papers addressing the issue in contexts as varied as Europe, Latin America, and the internet, including an early draft of this chapter. Separately, this author (Gould 2014a) has investigated whether Ostrom's principles can serve as a model to explain the long survival of community-based economic development projects linked to heritage sites.

Hess (2008:14), one of Ostrom's principal collaborators, has prepared a compendium of "new commons" studies in which she has identified several examples in which discourse on the commons has entered the heritage literature through appraisals of the negative impact of privatization on tangible and intangible heritage. The governance of a "knowledge commons," which as Cunningham (1991) explored years ago incorporates many aspects of indigenous heritage, has been examined in depth by political scientists (Hess and Ostrom 2011) and by lawyers (Frischmann et al. 2014; Madison et al. 2009-10). Indeed, the very notions of "new," "knowledge," or "cultural" commons open a broad new avenue for consideration of cultural and heritage resources from the standpoint of the theory and practice of commons management.

However, the commons-related scholarship in archaeology and heritage management proceeds too often without sufficient clarity regarding the implications of the theoretical roots and critical operational aspects of the work by Ostrom and others. For example, Zhang (2012) and Carman (2005) each selectively adopted some of Ostrom's (1990) governance principles for common pool resources (CPR) to justify their arguments about the relevance of Ostrom's model to heritage management, while omitting others of Ostrom's principles that are essential to Ostrom's reasoning but inconvenient to their arguments (see Gould 2014a:139-143). Neither Alonzo González et al. (Chap. 11 this volume) nor Colloredo-Mansfield and Antrosio describes in detail the governance of the projects on which they report, even though it is clear from Ostrom's work that the details of governance are critical. Some of the chapters in Bertacchini et al.'s volume (Barrère et al. 2012; Fiorentino and Friel 2012) describe as "commons" collaborative structures that more resemble the networks of interaction that integrate industrial clusters (Porter 1998) than they do models for the governance of complex commons. Furthermore, Bertacchini et al. (2012:247), based on Zhang's chapter, express the belief that a CPR model such as Ostrom's can be applied "easily" to managing and preserving heritage resources. As we shall see in the course of this chapter, this view is naïvely optimistic about the conditions necessary to achieve effective commons governance in light of the particularly complex array of stakeholders who will claim a seat at the table when discussing the governance of heritage.

It is not too early, in other words, to step back and inquire more deeply into the nature of the commons, the theory underlying commons analysis, and in particular the central issue in commons scholarship: governance. This chapter seeks to illuminate the complexities of applying commons concepts to the unique circumstances that face the heritage disciplines and suggest a path forward for research and field projects that can help realize the full potential of the commons concept in this discipline. 


\section{Defining the Commons}

Confusion over the application of the commons concept often begins with the word itself. What is this thing labeled a commons? First, two terms that often are used and conflated in the literature, commons and common pool resource, merit unbundling.

In general, economic analysis of the "commons" emphasizes the property aspects of resources that are owned in common. In the language of economists, "commons" may be seen as resources that are non-rivalrous (one person's use does not detract from another's) and non-excludable (it is essentially impossible to prevent others from using the resource). Commons in this sense are "public goods." The classic example is national defense or a large public park. In the case of public goods, a central issue is the management of "social dilemmas," such as "free riding" by community members who may, for example, pollute the air or ocean common, or extract water from a communal irrigation system but refuse to contribute to its upkeep. Economists take the view that that due to free riding, public goods either will be underprovided or overconsumed unless managed by governments or subjected to regulation. Typically, the "commons" in this sense are broadly the property of the general public.

Hess (2006) distinguishes between a commons-"a general term for shared resources in which each stakeholder has an equal interest"-and a common pool resource (CPR). CPRs traditionally are natural resources that are owned or used in common by a well-defined community. The most studied examples of CPRs include irrigation systems, forests, grazing lands, fisheries, and the like. Ostrom (1990:30) has defined a CPR as "a natural or man-made resource system that is sufficiently large as to make it costly (but not impossible) to exclude potential beneficiaries from obtaining the benefits from its use."

In other words, in the context of the standard economic model, exclusion from a CPR is possible albeit expensive, but unlike a public good the CPR is rivalrous - one person's appropriation from the common pool does affect another's. My cow grazing on the common pasture eats grass your cow cannot eat. The resource itself, in other words, is scarce rather than superabundant. Parsing Ostrom's definition carefully, two things become clear. First, a common pool, in her terms, is a system of resources that produces meaningful value for its users. Although crafted in the context of natural resources, the value of which are ordinarily accounted for in economic terms, this conception of CPRs clearly could encompass intangible resource systems-including cultural heritagethat yield social, cultural, or psychological value. What is essential, though, is that the resource be valuable to the members of the community charged with managing it. This is because the rivalry over the benefits flowing to the community from that valuable resource is the essential force incentivizing cooperative behavior to manage it sustainably. Second, whatever the nature of the CPR, it must be feasible ("costly but not impossible") for a defined group - a "community"- to regulate the appropriation of value from that resource. If regulation is not possible, for example because it is impossible to limit the number of users, then a CPR cannot come into existence.

In recent years, research on the commons has shifted from its traditional environmental and agrarian roots to contemplate the "common" aspects of a growing range 
of man-made "resources." As noted earlier, Hess (2008) has proposed at least an interim categorization of these "new commons." She identified resources as diverse as open source software and intellectual property rights; shared environmental resources such as air, water, and the oceans; infrastructure ranging from roads to the radio spectrum to the internet; parks and sports teams; or public health systems and antibiotics. In light of her sweeping perspective on the nature of a "commons," Hess (2008:37) has proffered an alternative definition of the term "commons" for contemporary purposes: "A commons is a resource shared by a group where the resource is vulnerable to enclosure, overuse and social dilemmas. Unlike a public good, it requires management and protection in order to sustain it."

Hess' approach to the "new" commons is an inclusive and widely cited perspective. Her definition of the commons not only is broad enough to encompass many aspects of heritage, but she explicitly identified from the literature on the new commons references to several culturally related resources, including landscapes, tourism, nonprofit organizations, neighborhoods and their amenities, and Indigenous culture. These categories of cultural resources are very much in line with today's notions of both "tangible" and "intangible" heritage. While most economists would disagree with her that public goods do not require management and protection, they would agree on the need for governance of CPRs. Many archaeological and heritage resources seem to fall potentially within the ambit of the "new commons": Historic city cores; major and minor archaeological sites; sacred landscapes, places, and objects; cultural and ritual practices; traditional fine and performing arts; languages and symbols; and traditional knowledge of medicine, food, or other natural resources. As we shall explore later, these heritage commons are vastly more complicated than the communal environmental resources studied intensively in the early days of commons scholarship.

Observe, however, that even in Hess' broader conception of the commons Ostrom's two central points remain. Whether tangible or intangible, local or global, a commons is a valuable resource that is subject to being enclosed (privatized), overused, or otherwise vulnerable to disputes among those who benefit from it. To avoid those deleterious outcomes, the management and protection of that vulnerable resource-a system of governance-is at the core of Hess' concept as well. Without a functioning governance system, no commons can be managed to deliver benefits to a defined constituency. The nature of such systems and the property rights regimes that determine rights to own, manage, use, or exclude others from using the commons remains to be defined.

\section{Economic Theory and the Commons Discourse}

The tradition of commons scholarship with the broadest theoretical and practical consequences arose in the study of natural resource commons, a field built on neoclassical economic theorizing that emerged in response to the widely accepted conclusion in the 1970s that successful collective management of environmental commons was 
improbable if not impossible, an argument used to justify government interventions at all levels to protect environmental public goods. Neoclassical economic theory is based on the belief that most resources are best managed through the market mechanism by private actors who control the right to utilize particular economic resources. This conclusion is based on economists' psychological model, Homo economicus, which posits that all individuals act rationally and with complete knowledge, and that rational self-interest always will trump individuals' desire to cooperate. In the case of commonly managed resources, however, two seminal publications of the 1960s argued that unfettered private behavior will destroy any commons.

In "The Logic of Collective Action," Mancur Olsen (1965), a neoclassical economic theorist relying on the Homo economicus model, built a detailed political and economic argument that individuals, acting rationally, would predictably fail to engage in positive collective action. He did stipulate one potential exception, the behavior of small communities where social pressures might induce collaboration (Olsen 1965:165-167). Three years later, however, Garrett Hardin (1968), an ecologist, applied Homo economicus to a thought experiment that contemplated the behavior of individuals who share exactly those small commonly held resources. The example he chose was a classic English grazing commons. He concluded, based on the logic of "prisoners' dilemma" games, that in this case also, rational and self-interested actors were likely to overuse and destroy commons resources. In the process, through the title of his article, Hardin gave birth to "The Tragedy of the Commons."

The scholarly counter-attack to this neoclassical argument is personified today in the work of the late Elinor Ostrom and her collaborators. Beginning in the 1980s, they identified literally thousands of examples of commonly held natural resources throughout the world (DLC 2015). Examples ranged from grazing lands to fisheries to forests to irrigation systems that have been managed and protected by local organizations. Most of these common resources were managed though structures initiated and designed locally by the community members who benefitted from the collectively controlled resource. Surprised to find so many examples that confounded the predictions of neoclassical economists (Poteete et al. 2010), Ostrom and her collaborators turned to insights from the emerging fields of institutional and behavioral economics that were rewriting textbooks in the discipline at the same time.

Adherents to the New Institutional Economics, of whom Ostrom was one, focus on the consequences of the reality that key assumptions of Homo economicus and economic decision-making theory are not reflected in actual behavior. Individuals do not possess perfect knowledge, they do not make decisions rationally at all times, and they may with some predictability behave less than honestly (Brousseau and Glachant 2008; Williamson 1996, 1998; North 1990). Supporting these findings, behavioral economists inspired by research psychologists (Kahneman 2011; Akerlof and Shiller 2009; Camerer and Loewenstein 2004) have demonstrated through rigorous laboratory tests that, in fact, people routinely behave very differently than neoclassical economists posit. People make decisions using short cuts that ignore important information, they tend to be loss averse and misevaluate the risks they are facing, and their perception of facts and choices can be significantly influenced by 
the manner in which questions are framed or decisions posed. More promisingly, behavioral economists have also discovered in experiments that people do cooperate regularly and predictably, even when it is not in their personal best interest. In other words, the destructively self-interested model of human behavior that inspired Olsen and Hardin's conclusions is not a realistic depiction of actual human behavior either in field or laboratory settings (Gintis 2000).

Thus, there emerged a realization among economists that cooperative behavior is feasible, albeit difficult, if the proper context and incentives for collaboration exist (Ostrom 2005; Ostrom and Walker 2003). The character of that context, however, becomes critical. In a world where collaboration is possible but must occur in the context of imperfect information, non-rational decision making and potential dishonesty, institutional economists and commons scholars have come to emphasize the importance of the institutions that regulate activity in the marketplace and in the commons. These institutions, which establish the rights of a defined population to utilize and manage a common resource, are the means for governing the commons.

\section{The Nature of Governance Institutions}

Scholars of the new "knowledge commons," to which cultural commons are closely related, point out that the institutional structures to govern intangible resources may differ significantly from those for natural resource commons (Frischmann et al. 2014). Indeed, only in an idealized world is the locus for governance of a commonly held resource a simple matter. In the context of heritage and archaeology, at the smallest scale, "communities" that might be called upon to manage smaller archaeological sites or other forms of heritage often are assemblages of people who may not necessarily constitute a cohesive or historic community in any sense (Smith and Waterton 2009). Even in homogeneous small communities, family, tribal, political, and personal differences are highly likely (Gould 2014b). In some cases, communities may not perceive the officially sanctioned archaeological heritage at their doorstep as vital to their present-day interests (Leventhal et al. 2014).

Beyond the community level, governance is especially important because heritage resources are not artifacts of natural processes but rather are "constructed commons" (Madison et al. 2009-10) that have particularly complex issues of ownership and control. Ruin sites are constructed in the literal sense, and the contentions are well known: Government agencies, archaeologists, local communities, tourism operators, and international organizations such as UNESCO or the World Monument Fund may all claim a place at the governance table. A resource such as traditional medical knowledge may have private market value that can be "enclosed" when corporations obtain patents on traditional remedies. Each knowledge commons requires particular mechanisms to protect the knowledge and assure economic benefit to the community that produced the knowledge (Frischmann et al. 2014; Hess and Ostrom 2011; Finger and Schuler 2004). In the case of World Heritage Sites, the declaration that a site has "outstanding universal value" amounts to an invitation to 
individuals and organizations well beyond the boundaries of a local community to assert a stake in deciding its future (Labadi and Long 2010). When cultural resources cross modern-day political boundaries, as is the case for example for linguistic or cultural groups that span modern-day borders, numerous nation-states and diaspora groups will be engaged, each with differing legal concepts, political relations to Indigenous communities, and plans and capabilities to exploit cultural resources through, for example economic development through tourism (Hess 2008).

Thus, even if one accepts that each of these resources constitutes a "commons," the determination of the best means to manage that resource is a matter of considerable complexity. Commons scholars now argue that the governance of large-scale, complex commons may require multilevel solutions. This literature has arisen largely in the context of large-scale environmental commons such as regional water systems (see Ostrom 1990, Chap. 4) or global-scale commons challenges, such as ocean pollution or climate change, in which resources are not the property of any specific group and many diverse actors have a legitimate stake in their conservation and management. Multilevel governance structures are generally seen to require that action and responsibility be kept as close as possible to the bottom of the hierarchy. Higher level authorities would coordinate responses to problems, resolve differences among lower levels participants, and work toward the benefits of large scale that are only available when multiple small-scale units collaborate. Ostrom, in the principles we will discuss later, originally called these "nested" structures of governance but came later in her career (Ostrom 2010a, b) to focus on the concept of polycentric governance systems, a specialty of her husband and collaborator, Vincent Ostrom (Herzberg 2005; Wagner 2005). Polycentric systems consist of multiple centers of authority, such as a federal system of government, that share power in a partially hierarchical, partially coequal, and often competitive context.

In other words, the utility of the "commons" concept in practice depends prominently on whether a system can be devised to manage the value conflicts, contention for power, and differing views of local community members versus those of outsiders at the regional, national, or even global levels (Agrawal 2008; Platteau 2008). In some circumstances, commons in the heritage context may approximate natural resource CPRs - locally situated and potentially ripe for local management. In others, World Heritage Sites for example, the constituencies are so varied that the governance of such a "commons" would be complex and polycentric. Either way, the essential message of the economics-based literature on the commons is that under inevitably contentious conditions, commons are only manageable through effective governance systems.

So, what exactly are these "governance institutions"? North (1990:4) provided a most accessible definition when he defined institutions to be "the rules of the road." That is, institutions that are created to control the use of commons can be expressed in laws or regulations, contracts, informal agreements, or even taboos. Penalties for infraction of the rules can be physical, such as exclusion from the commons community, monetary, such as fines or penalties, or psychological, such as shunning. The construction of institutions to manage the conflicts inherent in commons has been the object of study by scholars for several decades. The best known set of 
principles for designing governance structures for CPRs are those Ostrom (1990:88104) articulated in Governing the Commons:

1. The individuals or households who have rights to withdraw resource units from the CPR - the appropriators - must be clearly defined, as must be the boundaries of the CPR itself.

2. The rules for appropriating resources from the CPR must be congruent with local conditions.

3. The operational rules of the CPR may be modified though collective choice arrangements that give most individuals the right to participate.

4. Those who monitor appropriations from the CPR are either accountable to the appropriator or are themselves the appropriators.

5. When appropriators violate the rules, they are subject to a schedule of graduated sanctions depending on the severity of the infraction.

6. Low cost, efficient mechanisms are rapidly available to resolve conflicts among the appropriators.

7. The community of appropriators should have minimal recognition by external government authorities of their right to organize.

8. And, for CPRs that are elements of larger systems, all of these rules are organized in multiple layers of nested enterprises that assign responsibilities to the lowest possible levels in the structure.

The governance mechanisms embedded in these principles were distilled from numerous long-surviving CPR regimes that Ostrom and her colleagues studied and she illustrated in her book. Although concise, even these principles admit of myriad nuances of detail in the formation of institutions. Furthermore, Agrawal (2008) has compared Ostrom's list with two other major compendiums of CPR governance principles (Baland and Platteau 1996; Wade 1988). From the three studies, he identified as many as 35 "enabling conditions" for sustainable CPR management, the importance of which vary with the nature of the resource system, the characteristics of the group managing it, the institutional arrangements in place, and the external context. Madison et al. (2009-10) propose that the evaluation of competing theories and environmental variables is necessary to identify the governance principles best suited to the diverse circumstances affecting commons governance in the cultural sector. And none of this takes fully into account the challenges of governing amorphous knowledge commons that span numerous legal, governmental, and cultural boundaries (Hess and Ostrom 2011).

\section{Structuring Commons Governance in Heritage}

The discussion to this point has suggested, among other things, that heritage has many forms, geographies, and constituencies: local communities, national and regional governments, international organizations from UNESCO to the heritage NGOs, nonprofit organizations, for-profit cultural heritage management companies, 
tribal governments, private-public partnerships. The length of the list and the diversity of stakeholders illuminate the difficulty of creating governance structures for heritage. How, then, should one think about establishing governance rules? One useful approach was developed by Sassen (2006) when she traced the evolution of the European nation state and its ultimate integration into a globalized economic and political system.

In Sassen's view the struggle, then as in today's globalized world, was over the consolidation of three aspects of political power: Consolidation of control over Territory; the securing of Authority, or legitimacy, to act; and definition of the domain of Rights, or specific empowerments, to take action (collectively, in Sassen's formulation, "TAR"). Sassen argued that the globalized nation-state operates in a complex context in which traditional nation-state TAR is undermined by global institutions at the same time that it is adapting to and integrating itself into new forms of globalized governance regimes in order to preserve national institutions. The international, national, and local contexts that define points of contention over tangible and intangible heritage parallel this situation.

National heritage agencies have legal mandates and institutional incentives that often are inconsistent with governing heritage resources through mechanisms that are centered in local communities. Global institutions, such as the World Bank or UNESCO, also assert a stake in the traditionally nation-based management of heritage. Acknowledgment of Indigenous rights creates new pockets of territory-either physical preserves or rights over intangible heritage - for which authority to govern often is lodged in entities that may be opposed to both national and global actors. International actors, such as heritage NGOs, have their own agendas (Hopgood 2006; Bob 2005), and funding can be manipulated by national governments or international NGOs to dictate the authority, right, and capacity to manage heritage through their control over the allocation of funds. Meanwhile, local stakeholders may be at odds with all of the outside actors.

In short, in the heritage context, authority and the right to manage heritage resources (which are the "territory" in this analogy) clearly are jumbled in ways that make the creation of commons-based governance structures in heritage highly problematic. Today, the authority and right to govern the "territory" of large-scale heritage resources rarely are aligned with community organizations, even when they are obvious candidates to manage that heritage. By and large, prominent heritage resources are managed through national agencies under the influence and oversight of archaeologists, nongovernmental organizations, international government organizations such as UNESCO, and others who reside outside communities physically. With the well-known exception of indigenous communities in Australia, New Zealand, and the United States (but see Leventhal et al. 2014; Pyburn 2014; Gould and Paterlini, Chap. 10 this volume), there are few documented examples of situations where the authority and right to manage their own heritage have been devolved even to long-standing and well-defined local communities. The situation is more complex where the "territory" of a particular form of heritage is embedded within a diverse population center, covers a large geography, or involves diaspora communities. This is particularly true where heritage resources acquire significance on the 
national or international agenda, such as sites with World Heritage designation or sites that are central to national origin stories. In those cases, governance that is community centered may in fact be impossible and even the construction of polycentric models to govern a "constructed commons" will be politically and practically challenging.

Among smaller scale heritage resources, such as particular archaeological sites, legal authority to govern a heritage resource must be aligned with the "territory" encompassing that resource if commons-based governance is to be successful. Even then, the legal, political, financial, and organizational contexts must be aligned to endow some "community" entity with appropriate rights and capacity to manage the resource. In other words, national heritage agencies would need to devolve management authority to local actors yet facilitate them with financing and capacitybuilding training. Furthermore, because the governance system must reflect local social, economic, legal, political, and cultural practices, these rules cannot be imposed from outside the community. Each local heritage enterprise "modeled" on principles such as Ostrom's will need to devise its own governance rules and institutions.

\section{Case Studies in Heritage Commons Management}

Due to the hegemony of state actors-ministries of culture and the like-over the most significant heritage and archaeological sites, examples are scarce of direct community management of archaeological sites by organizations structured on a commons model. Many ecomuseums (Davis 2011) have lengthy histories managing communal heritage resources such as community museums, and the well-known community-managed museum in Agua Blanca, Ecuador (McEwen et al. 2006; Hudson and McEwen 1987) presents many features of commons management. At least one report that addresses the governance of a long-running community archaeology project (Faulkner 2009) reveals structures and conflicts familiar in the commons literature. However, in no case has the governance of a community-managed archaeological or heritage site been studied specifically for adherence to commons models such as the one developed by Ostrom.

However, examples do exist of long-surviving community-based economic development organizations that are associated with heritage sites. Rather than managing sites themselves, these projects tend to be community-based activities that seek to extract economic value from the flow of tourists visiting sites, making the tourists themselves the "common" resource. This is increasingly the sort of project undertaken by archaeologists seeking to create economic opportunities in communities rich in archaeological and heritage resources. The projects of the Sustainable Preservation Initiative (www.sustainablepreservation.org) and the Global Heritage Fund (www.globalheritgefund.org) are but two examples of projects sponsored by numerous non-governmental organizations and individual archaeologists (for other examples, see Burtenshaw and Gould 2015). The objective of these projects is to 
promote local economic development that is identified with the heritage resource, in the hope that economic benefits will encourage communities to prevent looting and support preservation of archaeological sites or heritage resources.

This author has investigated (Gould 2014a) two such projects to determine specifically whether their long histories of successful operation reflect community practices in line with Ostrom's management principles: the Asociacíon Inkallaqta, founded in 1998 in Raqchi, Peru, and the Maya Centre Women's Group, founded in 1987 in Maya Centre, Belize. A brief comparison of each group with the other and with Ostrom's principles is instructive regarding the conditions under which the commons concept is relevant to archaeology and heritage management.

Each of these groups was founded on the impetus of local residents-one an artisan, one the village mayor-not by outside government, NGO, or academic "experts." Each was created in order to enable local residents to take advantage of anticipated growth in tourism-related business as a result of the creation (of the Coxcomb Basin Wildlife Sanctuary in the case of Maya Centre) or the promotion (of the Inca Temple to Viracocha that dominates Raqchi) of heritage-related tourism destinations adjacent to the villages. In each case, the common pool economic resource that these two organizations were created to manage collectively is the flow of tourists through the villages, not the heritage itself. The function of each group is to organize the exploitation of tourist flows by creating a collectively owned organization that regulates the sale of handicrafts and other materials to tourists. Each organization mirrors Ostrom's design principles quite clearly: Boundaries that determine who may participate in exploiting the common resource are very clear; each organization is governed by collective choice voting procedures through which the rules governing the group's craft-sales practices are established; each has mechanisms to monitor compliance with the rules and has a graduated series of sanctions depending on the degree of infraction; and each operates within a legal context that empowers local communities to organize in this fashion.

However, the specific mechanisms for resolving conflicts among the members and managing the businesses of these two cooperative ventures could not be more different, which itself is consistent with Ostrom's expectation that such rules would be highly dependent on local conditions. In Raqchi, the Asociacíon Inkallaqta is a cooperative of individual vendors who purchase and sell their own merchandize at their own tables in the village plaza. The association's regulatory role is limited to establishing dress codes, table dimensions, price controls, and rules on vendor demeanor, and to managing the rotation scheme that ensures each vendor has regular and equal access to the best sales locations in the plaza. The group handles very little cash itself and manages members' access to the flow of tourists through the village in a manner that strongly resembles the rules created by collectives of individual fisherman to manage the harvest from common fisheries, such as those studied in coastal Turkey by Berkes (1986).

The Maya Center Women's Group, by contrast, has created a shop in which all members' goods are sold by rotating crews of three members who handle visitor traffic, record sales, and monitor one another. Due to a complex history of relocation and family discord in Maya Centre, the small village is characterized by extreme 
distrust among the residents. As a result, the women's group has evolved a substantial set of obligations for its members and a very complex system to record sales, manage cash receipts, monitor compliance with rules, and resolve differences among the members. The rules involve extreme transparency in financial transactions, graduated penalties for failure to perform duties, and novel electoral mechanics designed to insulate the group from the community's otherwise acrimonious politics.

Thus, even where the contours of specific community projects may be mapped readily onto Ostrom's principles of self-organization and self-regulation of common resources, the specific details of governance can differ dramatically from one case to the next, depending on the social, cultural, and political context within which the organization is situated. Where economic incentives are appropriate, organizations that manage tourist resources-or even sites themselves-can be established on a commons platform, but the evidence from Raqchi and Maya Centre underscores the critical point that there will be no formulaic means for structuring such an organization, and that it will be more likely to succeed if it is initiated and governed by local residents according to rules they establish and enforce themselves.

\section{The Commons Model in Heritage Management}

Archaeologists and heritage managers intrigued by the commons model may look wistfully at reports by scholars of communal management of environmental resources and envision a model for organizing their own successful community projects. Too often, however, they do so without close inspection of the political, social, and economic complexities of governance that underlies successful environmental commons management. Furthermore, the complicated imbrication of interests among various local, national, and international stakeholders in heritage resources makes creating such community-based organizations in the heritage context even more complicated than managing forests, fisheries, or irrigation systems. Until national and international actors are prepared to authorize local community groups to manage archaeological sites or heritage resources, and until those groups are given the appropriate authority and rights to act, commons management of heritage will largely remain a chimera.

Nonetheless, the threats to tangible and intangible heritage persist and the disenfranchisement of local communities by global governmental and economic forces continues. The existence of a few examples demonstrates that the commons model can be relevant to heritage. There is thus motivation to move the discourse forward and to implement more and better projects. To do so, there needs to be an agenda for future research. That agenda should have at least five elements:

First, the heritage sector needs to contribute directly to the research effort of the commons community. A search of the massive Digital Library of the Commons (DLC 2015) reveals that of the thousands of studies of commons governance recorded there, a mere handful address contemporary archaeological or heritage 
management concerns. Existing community-based projects, and they do exist, need to be identified, their social, political, and economic contexts and governance mechanics described, and their commonalities_or lack thereof-analyzed. This research needs to redress the crippling lack of actual data in heritage studies. Ethnographic analysis and even anecdotal reports can be useful to provide context, but to make this research implementable, specific details on governance structures and rules, and data on economic and non-economic performance of the ventures are essential. Such research will require both an anthropological attention to the details of each institution and a collective effort to amass sufficient comparable data to permit metastudies that identify and delineate models that may be useful and the contexts in which they may be applied.

Second, archaeologists need to respond in specific terms to the unique governance challenges that arise with heritage resources. The reigning structure of cultural heritage management - everything from UNESCO's insistence on operating at the nation-state level to archaeologists' concern for stewardship of the archaeological record - may need to be revisited if the ultimate goal is to devolve authority and rights over heritage to local-level stakeholders who will otherwise be barraged and constrained by international, national, scholarly, and corporate stakeholders.

Third, this will be an inherently interdisciplinary undertaking. Research into environmental commons has engaged economists, political scientists, historians, anthropologists, lawyers, and scientific technicians in the search to understand even relatively straightforward commons such as irrigation systems or communal grazing lands. Managing World Heritage Sites or intangible heritage as commons will be more complex. As Bardhan and Ray (2008) have demonstrated, cross-disciplinary, if not pan-disciplinary, inquiry is fraught with misunderstandings, biases, and conflicting myopias. Nonetheless, heritage practitioners will need to appropriate research techniques and analytical models from disciplines with a longer history of commons scholarship in order to construct approaches to managing heritage resources that integrate concerns at the local, national, and international levels.

Fourth, archaeologists and heritage managers need to engage on a practical level with NGOs, government entities, and corporations to experiment with innovative solutions, especially polycentric and multilevel approaches to heritage management. Such projects will require the discipline to abandon reflexive resistance to cooperation with corporate or governmental institutions in favor of a willingness to consider the sort of compromise positions taken, for example, by the Nature Conservancy in the environmental field. Ultimately, reconciling the interests of the complex network of heritage stakeholders likely will require governance approaches that will employ elements of classic CPR models, American- or British-style nonprofit models, public-private partnerships, and government-sponsored quasi-NGOs, or Quangos as they are known in the United Kingdom.

Fifth and finally, this research needs to proceed in a spirit of humility toward the other stakeholders, particularly the members of communities most directly affected by heritage preservation and development. Ostrom's body of research is focused on communities that organize themselves to manage their resources. Other studies (Gould 2014a; Baland and Platteau 1996; Wade 1988) have identified the fundamental impor- 
tance of local leadership and local organization in the creation of sustainable entities. Even a simple commons can prove more complex to govern than outsiders are capable at the outset of perceiving (see Pyburn Chap. 13 this volume). In such circumstances, rules developed by those who must live with them will be far more robust. There are no "experts" in the creation of heritage commons, and the issues are so complicated on the ground that deference must be paid to the knowledge as well as the interests of local people in order to generate viable community-based enterprises.

\section{References}

Agrawal, A. (2008). Sustainable governance of common-pool resources. In P. Bardhan \& I. Ray (Eds.), The contested commons (pp. 46-65). Malden, MA: Blackwell.

Akerlof, G. A., \& Shiller, R. J. (2009). Animal spirits: How human psychology drives the economy and why it matters for global capitalism (Kindle Edition). Princeton, NJ: Princeton University Press. Retrieved from Amazon.com.

Alonso González, P. (2014). From a given to a construct. Cultural Studies, 28(3), 359-390.

Alonso González, P. (2015). Conceptualizing cultural heritage as a common. In P. F. Biehl, D. C. Comer, C. Prescott, \& H. A. Soderland (Eds.), Identity and heritage (pp. 27-35). Dordrecht: Springer International.

Arizpe, L. (2000). Cultural heritage and globalization. In E. Avrami, R. Mason, \& M. De la Torre (Eds.), Values and heritage conservation (pp. 32-37). Los Angeles: Getty Conservation Institute.

Baland, J.-M., \& Platteau, J.-P. (1996). Halting degradation of natural resources: Is there a role for rural communities? Oxford: U.N. Food and Agricultural Organization and Clarendon Press.

Bardhan, P., \& Ray, I. (2008). The contested commons. Malden, MA: Blackwell.

Barrère, C., Bonnard, Q., \& Chossat, V. (2012). Food, gastronomy and cultural commons. In E. Bertacchini, G. Bravo, M. Marrelli, \& W. Santagata (Eds.), Cultural commons: A new perspective on the production and evolution of cultures (pp. 129-150). Cheltenham, UK: Edward Elgar.

Berkes, F. (1986). Local-level management and the commons problem: A comparative study of Turkish coastal fisheries. Marine Policy, 10(3), 215-229.

Bertacchini, E., Bravo, G., Marrelli, M., \& Santagata, W. (Eds.). (2012). Cultural commons. Cheltenham, UK: Edward Elgar.

Bob, C. (2005). The marketing of rebellion. Cambridge: Cambridge University Press.

Brodie, N., \& Tubb, K. W. (Eds.). (2002). Illicit antiquities: The theft of culture and the extinction of archaeology. London: Routledge.

Brousseau, É., \& Glachant, J.-M. (Eds.). (2008). New institutional economics: A guidebook. Cambridge, UK: Cambridge University Press.

Burtenshaw, P., \& Gould, P. G. (Eds.). (2015). Archaeology and economic development. Oxford: Maney and Oxbow Books.

Camerer, C. F., \& Loewenstein, G. (2004). Behavioral economics: Past, present, future. In C. F. Camerer, G. Lowenstein, \& M. Rabin (Eds.), Advances in behavioral economics (pp. 2-51). New York, Princeton: Russell Sage Foundation and Princeton University Press.

Carman, J. (2005). Against cultural property: Archaeology, heritage and ownership. London: Duckworth.

Colloredo-Mansfeld, R., \& Antrosio, J. (2009). Economic clusters or cultural commons? The limits of competition-driven development in the Ecuadorian Andes. Latin American Research Review, 44(1), 132-157. 306-307.

Comer, D. (2012). Tourism and archaeological heritage management at Petra: Driver to development or destruction? New York: Springer. 
Comer, D. (2014a). Archaeological world heritage as a non-renewable resource: Threats from the Laissez-Faire world of tourism. Public Archaeology, 13(1-3), 121-132.

Comer, D. (2014b). Archaeology as a global public good and a local identity good. In P. F. Biehl, D. Comer, C. Prescott, \& H. A. Soderland (Eds.), Identity and heritage: Contemporary challenges in a globalized world (pp. 11-26). London: Springer.

Cunningham, A. B. (1991, July 31). Indigenous knowledge and biodiversity: Global commons or regional heritage? Cultural Survival Quarterly, p. 4.

Davis, P. (2011). Ecomuseums: A sense of place (2nd ed.). New York: Continuum International Publishing Group.

DLC. (2015). Digital library of the commons. Retrieved July 5, 2015, from http://dlc.dlib.indiana. edu/dlc/.

Dowee, M. (2009). Conservaion refugees: The hundred-year conflict between global conservation and native peoples. Cambridge: MIT Press.

Faulkner, N. (2009). The sedgeford crisis. Public Archaeology, 8(1), 51-61.

Finger, J. M., \& Schuler, P. (Eds.). (2004). Poor people's knowledge: Promoting intellectual property in developing countries. (Trade and development series). Washington, DC: The World Bank and Oxford University Press.

Fiorentino, P., \& Friel, M. (2012). Structure and evolution of two cultural commons: Italian futurism and Milanese design. In E. Bertacchini, G. Bravo, M. Marrelli, \& W. Santagata (Eds.), Cultural commons: A new perspective on the production and evolution of cultures (pp. 107128). Cheltenham, UK: Edward Elgar.

Frischmann, B. M., Madison, M. J., \& Strandburg, K. J. (Eds.). (2014). Managing knowledge commons. Oxford: Oxford University Press.

Gintis, H. (2000). Beyond homo economicus: Evidence from experimental economics. Ecological Economics, 35, 311-322.

Gould, P. G. (2014a). Putting the past to work: Archaeology, community and economic development. Ph.D. thesis, University College London, London (Available from UCL Discovery at http://discovery.ucl.ac.uk/1427269).

Gould, P. G. (2014b). A tale of two villages. Public Archaeology, 13(1-3), 162-175.

Hardin, G. (1968). The tragedy of the commons. Science, 162(3859), 1243-1248.

Herrera, A. (2014). Commodifying the indigenous in the name of development: Archaeology and heritage management in the XXI century central Andes. Public Archaeology, 13(1-3), 69-82.

Herrera Wassilowsky, A. (Ed.). (2013). Arqueología y Desarollo en América del Sur. Bogotá: Ediciones Uniandes \& Instituto de Estudios Peruanos.

Herzberg, R. (2005). Commentary on Richard Wagner's "Self-governance, polycentrism, and federalism: Recurring themes in Vincent Ostrom's scholarly oeuvre". Journal of Economic Behavior \& Organization, 57(2), 189-197.

Hess, C. (2006). Research on the commons, common-pool resources, and common property. Retrieved July 6, 2015, from http://dlc.dlib.indiana.edu/dlc/contentguidelines.

Hess, C. (2008). Mapping the new commons. Paper presented at the Governing Shared Resources: Connecting Local Experience to Global Challenges; 12th Biennial Conference of the International Association for the Study of the Commons, University of Gloucestershire, Cheltenham, July 14-18, 2008.

Hess, C., \& Ostrom, E. (Eds.). (2011). Understanding knowledge as a commons: From theory to practice. Cambridge, MA: MIT Press.

Hopgood, S. (2006). Keepers of the flame: Understanding Amnesty International. London: Cornell University Press.

Hudson, C., \& McEwen, C. (1987). Focusing pride in the past: Aqua Blanca, Ecuador. Museum, 39(2), 154.

Kahneman, D. (2011). Thinking, fast and slow. New York: Farrar, Straus and Giroux.

Labadi, S., \& Long, C. (Eds.). (2010). Heritage and globalisation. (Key issues in cultural heritage). London: Routledge. 
Leventhal, R. M., Espinosa, C. C., Pat, E. M., \& Demetrio, P. C. (2014). Community and heritage: A community heritage project in Tihosuco, Quintana Roo, Mexico. Public Archaeology, 13(13), 211-223.

Madison, M. J., Frischmann, B. M., \& Strandburg, K. J. (2009-10). Constructing commons in the cultural environment. Cornell Law Review, 95(4), 657-710.

McEwen, C., Silva, M.-I., \& Hudson, C. (2006). Using the past to forge the future: The genesis of the community site museum at Agua Blanca, Ecuador. In H. Silverman (Ed.), Archaeological site museums in Latin America (pp. 187-216). Gainesville: University Press of Florida.

Meskell, L. (2012). The nature of heritage: The New South Africa. Malden, MA: Wiley-Blackwell.

North, D. C. (1990). Institutions, institutional change, and economic performance. Cambridge, UK: Cambridge University Press.

Olsen, M. (1965). The logic of collective action: Public goods and the theory of groups. Cambridge, MA: Harvard University Press.

Ostrom, E. (1990). Governing the commons. Cambridge, UK: Cambridge University Press.

Ostrom, E. (2005). Understanding institutional diversity. Princeton, NJ: Princeton University Press.

Ostrom, E. (2010a). Beyond markets and states: Polycentric governance of complex economic systems. The American Economic Review, 100(3), 641-672.

Ostrom, E. (2010b). Polycentric systems for coping with collective action and global environmental change. Global Environmental Change, 20(4), 550-557.

Ostrom, E., \& Walker, J. (Eds.). (2003). Trust and reciprocity. New York: Russell Sage.

Platteau, J.-P. (2008). Managing the commons: The role of social norms and beliefs. In P. Bardhan \& I. Ray (Eds.), The contested commons (pp. 25-45). Malden, MA: Blackwell.

Porter, M. E. (1998). Clusters and the new economics of competition. Harvard Business Review, 76(6), 77-90.

Poteete, A. R., Janssen, M. A., \& Ostrom, E. (2010). Working together: Collective action, the commons and multiple methods in practice. Princeton, NJ: Princeton University Press.

Pyburn, K. A. (2014). Preservation as 'disaster capitalism': The downside of site rescue and the complexity of community engagement. Public Archaeology, 13(1-3), 226-239.

Sassen, S. (2006). Territory, authority, rights: From medieval to global assemblages. Princeton, NJ: Princeton University Press.

Smith, L., \& Waterton, E. (2009). Heritage, community and archaeology. London: Duckworth.

Wade, R. (1988). Village Republics: Economic conditions for collective action in South India. Cambridge, UK: Cambridge University Press.

Wagner, R. E. (2005). Self-governance, polycentrism, and federalism: recurring themes in Vincent Ostrom's scholarly oeuvre. Journal of Economic Behavior \& Organization, 57(2), 173-188.

Williamson, O. E. (1996). The mechanisms of governance. New York: Oxford University Press.

Williamson, O. E. (1998). The institutions of governance. The American Economic Review, 88(2), $75-79$.

Zhang, Y. (2012). Heritage as cultural commons: Towards an institutional approach of self governance. In E. Bertacchini, G. Bravo, M. Marrelli, \& W. Santagata (Eds.), Cultural commons (pp. 153-177). Cheltenham, UK: Edward Elgar. 